metres measure of the uranium reagent is placed in a porcelain basin, five cubic centimetres of the sodium acetate added, and the mixture heated nearly to boiling. The solution containing the phosphate (either the standard sodium phosphate solution or the urine under examination) is then gradually added from a burette, the mixture being well stirred after each addition. The end of the reaction is indicated when the rich brown colouration, produced when a drop of the liquid from the basin is removed with a glass rod and added to one of a series of little heaps of powdered potassium ferrocyanide (a few grains in each heap) placed on a porcelain plate, ceases to be formed. The volume of phosphate solution or urine required is then read off in the burette. A much more definite "end-reaction" is obtained when the phosphate is run into the uranium solution (as above) than when the reverse method is followed, since it is easier to observe the disappearance of the brown uranium ferrocyanide than its formation.

Supposing on standardising the uranium solution 50.0 cubic centimetres of the standard phosphate solution were added to the uranium solution in the basin before a brown colouration ceased to be given with the indicator. Then, since 50.0 cubic centimetres phosphate solution $=0.100$ gramme $\mathrm{P}_{2} \mathrm{O}_{5}, 20.0$ cubic centimetres of uranium solution $=0.100$ gramme $\mathrm{P}_{2} \mathrm{O}_{5}$ and thus 1.0 cubic centimetre is equivalent to 0.005 gramme $\mathrm{P}_{2} \mathrm{O}_{5}$. In an experiment 20 cubic centimetres of the uranium reagent required $54 \cdot 5$ cubic centimetres of a sample of urine before the brown colouration ceased to appear. Hence 54.5 cubic centimetres of the urine contained $0 \cdot 100$ gramme $\mathrm{P}_{2} \mathrm{O}_{5}$; equal to 0.183 gramme $\mathrm{P}_{2} \mathrm{O}_{5}$ per 100 cubic centimetres of the sample.

Urea, sugar, and albumin.-The usual methods for the determination of urea and sugar in urine are well known and we have nothing new to state regarding them. For the detection of minute traces of albumin in urine we have found salicyl-sulphonic acid (sulpho-salicylic acid) to exceed in delicacy many of the commonly employed reagents. In applying the test it is simply necessary to add a few crystals of the salicyl-sulphonic acid to a little of the clear urine and agitate the mixture, when the appearance of a turbidity or the formation of an actual precipitate will indicate the presence of albumin. When only minute quantities of albumin are present the turbidity is best observed against a black background. The precipitate produced by an albumin or globulin is not affected by heat, while that due to albumoses or peptones dissolves, reappearing as the liquid cools.

\section{NEPHRECTOMY AFTER INJURY.}

BY H. T. COX, L.R.C.P., L R.C.S. IREL., DEPUTY INSPECTOR-GENERAI, B.N.

THE patient was a youth, aged 19 years, a stoker on H.M.S. Pyramus. On the afternoon of Dec. 22nd, 1903, owing to the heavy rolling of the ship, he was thrown against a guard plate in the stokehold, striking his right side. When first seen he was collapsed and complained of great pain at the seat of injury; he romited twice and voluntarily emptied the bladder, the fluid consisting of almost pure blood. The patient was admitted to the Royal Naval Hospital, Malta, at 6.30 P.M., four hours after the accident. He was then collapsed, his face was blanched, and he had a weak thready pulse. There was complete loss of resonance in the right flank reaching almost to the middle line in front. A catheter was passed and a quantity of well-mixed blood and urine was drawn off. The bladder was washed out with boric lotion, a vermiform clot coming away. Sulphate of strychnine ( ${ }^{1}$ th of a grain) was given hypodermically. At 8.30 P.M. the patient was almost pulseless, very restless, and the respirations were of a sighing character. A few ounces of deeply blood-stained urine had been passed, showing that hæmorrhage still continued. As he was rapidly getting worse it was decided to operate immediately.

Ether having been administered, an incision five inches in length was made from the middle of the last rib downwards and forwards towards the iliac crest. The right kidney was exposed and examined after a large quantity of blood clot had been turned out. The organ was found to be lacerated badly, so it was cleared from the surrounding fat and drawn inta the mouth of the wound. The pedicle was then tied with catgut and divided and the kidney was removed. The wound was well washed out with boric lotion and ligatures were applied to one or two bleeding points. Deep and superficial sutures were inserted, a large size drainagetube being left in the lower angle of the wound. Half a pint of sterilised normal saline solution was injected into the median basilic vein during the operation and at its conclusion sulphate of strychnine (1 $1^{1}$ th of $a$ grain) was administered hypodermically. The patient bore the operation very well, his pulse being better afterwards than before. The kidney was found to be torn completely in half transversely and was also lacerated longitudinally along its inner border. The patient made uninterrupted progress towards recovery. The first urine passed was slightly blood-stained but by the following morning it was quite clear and contained no trace of blood. 33 ounces of urine were passed on the first day, after which the quantity increased and was generally between 40 and 60 ounces. The largest amount measured was 89 ounces passed on the ninth day. The temperature never rose above $101^{\circ} \mathrm{F}$. The drainage-tube was removed after 36 hours. On Jan. 2nd, 1904, the wound was healed except for a sinus at its lower angle, where the tube had been. On the 6th the patient was allowed to sit up and convalescence was rapid.

This case is of interest, as such very extensive injury to the kidney without other viscera being involved is, I think, unusual.

Malta.

\section{Climital a dintes:}

MEDICAL, SURGICAL, OBSTETRICAL, AND THERAPEUTICAL.

\section{CARDIAC SOUNDS ENORMOUSLY INOREASED BY} SURGICAL EMPHYSEMA.

By W. J. C. KeAts, M.R.C.S. ENG., L.R.C.P. LOND., D.P.H.,

MEDICAL SUPERINTENDENT, ST. GILES INFIRMARY, CAMBERWELL.

I REPORT the following case as being of interest, as I am not aware, from my limited reading, of a similar case having been reported.

The patient was a female, 38 years of age. She had been drinking heavily and in the course of a quarrel with her husband she jumped out of a window and was brought into the infirmary on the police ambulance. On admission she had a few contusions about the face and a small bruise of about the size of half-a-crown at the junction of the third and fourth right ribs with the sternum. Nine hours afterwards examination of the chest revealed that the bruising in this situation had nearly gone. On listening to the cardiac sounds they appeared to be normal at the apex but upon going up towards the aortic area a very slight systolic murmur became apparent ; when, however, the stethoscope was placed on the sternum and over an area about three inches by three inches situated over the third and fourth right ribs near the sternum most alarming cardiac murmurs were heard. Neither in aneurysms nor with the phonendoscope have I heard sounds or murmurs so amplified. The skin over this area was raised about a quarter of an inch by surgical emphysema. At first an aneurysm near the bursting point, causing rupture of the pleura, was thought of, for a thrill could be very distinctly made out. Gradually as the pressure of the stethoscope was increased it cut out the air and I was enabled to listen through the ordinary chest wall, the result being that the alarming sounds immediately subsided and the sounds of the heart were heard quite dis. tinctly. As the pressure of the stethoscope was diminished the abnormal sounds returned again to their full intensity. A more minute examination detected increased movement of the third and fourth ribs, due apparently to a fracture close to their junction with the sternum.

The following points of interest appear in this case. 1. The sounds and situation closely simulating a sudden bursting through the pleura of an aneurysm (although of course there were features against this). 2. The peculiar vibratory thrill in the emphysematous patch set ap by each beat of the heart. 3. The extraordinary amplification of the 